\title{
Sodium leak blots Japan's nuclear prospects
}

Tokyo. The future direction of Japan's nuclear programme has been put in question both by the technical implications of last month's liquid sodium leak at the fast breeder reactor Monju, and by a growing scandal over an apparent attempt to suppress a video film of the accident scene.

The discovery that the leak was due to a fracture of one of many thermal probes in the sodium cooling system means that the reactor, at Tsuruga on the coast of the Japan Sea, may have to be closed down for several years for repairs and redesign.

In addition, moves by the Power Reactor and Nuclear Fuel Development Corporation (PNC) to prevent some revealing video footage taken shortly after the accident from reaching the media have undermined public trust in the corporation, which is responsible for implementing all research and development in relation to nuclear power in Japan.

Last week, an X-ray inspection of the leak site by a team from the Science and Technology Agency (STA), the government agency that administers PNC and Monju, revealed that liquid sodium in the secondary cooling system had leaked out through the fracture of a probe that measures the temperature of the sodium coolant.

The probe, which is encased in a stainless steel cylinder and extends about $18 \mathrm{~cm}$ into the liquid metal, apparently snapped off at a point where the cylinder rapidly tapers from 2 to $1 \mathrm{~cm}$ in diameter (see diagram). The liquid sodium leaked out through the broken cylinder. The STA experts do not yet know why the cylinder broke. It may have been the result of an isolated defect, such as a hairline fracture, in that particular probe, or, alternatively, to a more fundamental flaw in the design of the probes, of which there are 48 in the reactor's cooling system.

One theory under consideration is that vortices shed from the probe as the flow of liquid sodium varies between zero and 5 metres per second may have caused the probe to vibrate and eventually to fracture.

Similar probes were used for 20 years without problem in Monju's predecessor, the experimental fast breeder Joyo. But the Joyo probes were shorter and tapered more gradually, and PNC officials admit that no long-term vibration tests were carried out on the new design of probes used in Monju.

As serious as this admission was, an even greater public uproar has been caused by the revelation that PNC officials tried to hide from the public a videotape that they recorded a few hours after the accident in the room where sodium leaked, and that they also heavily edited other video footage that was released to the press and television.

Under pressure from local government officials, who videotaped the area of leakage for themselves three days later, PNC officials first admitted on 20 December that order to remove sections showing sodium compounds dripping from the area around the thermal probe. This was apparently done in an attempt to play down the seriousness of the accident.

A subsequent investigation by the STA revealed that PNC had made another earlier video at about 2 a.m. on 9 December - a few hours after the accident — showing

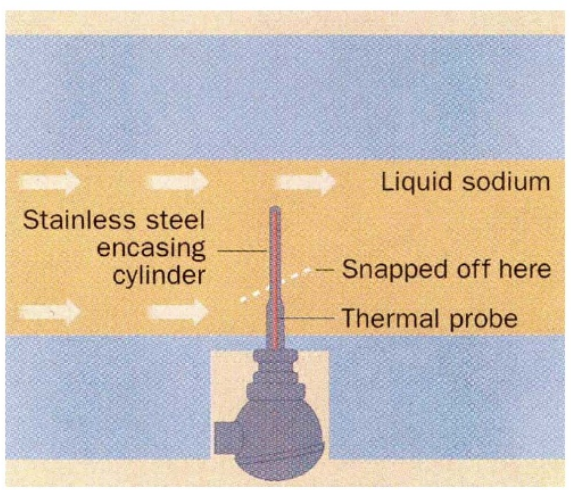

A fracture of the temperature probe seems to have allowed liquid sodium to leak out.

officials wearing silver protective suits in a room filled with white smoke produced by the leaking sodium.

PNC officials had attempted to hide this video footage from the public. They had also apparently lied in a report to the STA stating that no-one had entered the room where sodium leaked until 10 a.m. that morning. Following this revelation, four local PNC officials at the Monju site were demoted and moved to new positions elsewhere in the corporation.

But the matter has not rested there. The results of an internal investigation by PNC released last Friday (12 January) has revealed that, despite claims by officials at the corporation's headquarters in Tokyo that they were unaware of the videotape taken by their local officials, a copy of the tape had in fact been viewed by ten head- they had edited a 4-minute video down to 1 minute before releasing it to the media, in

quarters staff the day after the accident.

After this latest admission, the STA decided to dismiss the head of PNC, Hiroshi Oishi. The next day, the PNC official in charge of the internal investigation, Shigeo Nishimura, leapt to his death from a hotel roof in Tokyo. Nishimura, deputy general manager of PNC's general affairs department, who was appointed by Oishi to head the investigation, is said to have written in a suicide note to Oishi, explaining that he was "exhausted by his duties". (It is a peculiarity of Japan that junior officials sometimes commit suicide if they play a role in getting their bosses into trouble, or if they feel burdened by knowing too much.)

It now seems likely, for both technical and political reasons, that Monju will not resume operations for at least several years. In particular, local government officials of Fukui Prefecture, where Monju is located, have emphasized that they will not allow operation of the reactor to be resumed until both they and the public are completely satisfied that the plant is safe.

The acting head of the Atomic Energy Commission, Yoshinori Ihara, has admitted that nuclear energy in Japan has "sustained a deep scar" with the Monju accident because it "lost the people's trust" in nuclear energy, in particular fast breeder reactors.

Japan has already had to delay and scale back its plans for recycling nuclear fuel and producing plutonium because of delays in the operation of Monju (see Nature 369, 596 ; 1994). Even so, the government is projecting that it will have about 70 tonnes of plutonium on its hands by 2010 , and it plans to burn up much of this in conventional reactors by mixing it with uranium.

But the Monju accident has increased public resistance to the use of plutonium in any kind of reactor. Although the government has yet to take an official stance, it now seems inevitable that Japan will, at the very least, have to scale back and/or delay its plans for nuclear fuel recycling even further.

David Swinbanks

\section{Russia appoints vice-premier for science}

Moscow. Russian science has received some unexpected support from the Kremlin in the form of a decree from President Boris Yeltsin announcing the appointment of 50year-old Vladimir Kinelev, head of the State Committee for Education, as a vice-premier for science and education.

It remains unclear what relationship Kinelev will have in his new post with Boris Saltykov, the Minister of Science and Technological Policy. Saltykov had been the vice-premier responsible for both science and education before the administration of these two activities was divided between the State Committee and the ministry.
Kinelev says that he was informed of his promotion by Viktor Chernomyrdin, the prime minister, rather than by Yeltsin himself. "An integrated system of science and education is being developed in Russia," Kinelev said last week. "Our target is to adapt this unique system quickly to the market economy, in order to create mechanisms for transferring new technologies to small and medium size business".

Science and education are expected to receive additional support in the near future from the recently elected State Duma, the lower chamber of the Russian parliament.

Carl Levitin 